\title{
Do mastoidectomy and type of graft affect tympanoplasty outcome in Egyptian children? A prospective randomized study
}

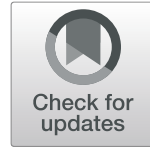

\author{
Ahmed Gamal Khafagy ${ }^{1,2^{*}}$ (D, Tamer S. Sobhy ${ }^{1}$ and Pretty O. Afifi ${ }^{1}$
}

\begin{abstract}
Background: The purpose of this study is to evaluate and compare surgical and hearing outcomes of tympanoplasty using temporalis fascia graft and tragal cartilage with or without mastoidectomy in children with tubotympanic chronic suppurative otitis media.

Two hundred children with chronic suppurative otitis media of tubotympanic type with perforation were included in this prospective randomized study. They were divided randomly into four equal groups according to operation done. Group I underwent tympanoplasty using temporalis fascia graft with cortical mastoidectomy, while in the second group, tragal cartilage was used as a graft with mastoidectomy. Groups III and IV were done without mastoidectomy, with tragal cartilage for group III and temporalis fascia for group IV. One-year follow-up was done for all patients to evaluate graft success (means without perforation nor retraction). Audiological evaluation was done for all children preoperatively and 6 months postoperatively for patients with successful graft uptake.

Result: There were 170 patients (85\%) with graft success postoperatively. Tympanoplasty using temporalis fascia graft showed highly statistically significant difference $(P<0.001)$ when compared to tragal cartilage as regards hearing improvement in patients with successful graft uptake, while there is no statistically significant difference as regards graft uptake $(P=0.039)$. Also, there is no statistically significant difference between different techniques with or without mastoidectomy $(P=0.165)$.

Conclusion: Tympanoplasty using temporalis fascia without cortical mastoidectomy is the surgery of choice in children between 10 and 16 years old with tympanic membrane perforation as it showed highly statistically significant difference when compared to tragal cartilage graft as regards hearing improvement, with no statistically significant difference regarding successfully graft uptake.
\end{abstract}

Keywords: Chronic suppurative otitis media, Mastoidectomy, Tympanoplasty, Graft uptake

\section{Background}

Chronic otitis media is any structural change in middle ear system associated with a permanent defect in tympanic membrane (TM) [1]. TM perforation with no associated middle ear inflammation and discharge is classified as COM mucosal inactive [2]. The usual causes are infection, atelectasis, ventilation tube insertion, and trauma [3].

\footnotetext{
*Correspondence: ahmedgamal_2489@yahoo.com

'Otorhinolaryngology Department, Faculty of Medicine, Ain Shams University, Cairo, Egypt

${ }^{2}$ Doha, Qatar
}

\section{Springer Open}

Children suffering from chronic suppurative otitis media of tubotympanic type (CSOM-TT) with permanent perforation usually present with intermittent ear discharge of variable duration and hearing loss [4].

Myringoplasty is the repair of a tympanic membrane perforation without ossicular reconstruction. It is one of the various surgical techniques for the management of CSOM-TT disease. The operation aims at closure of the perforation with a tissue graft [5].

Variable success rates have been reported for closure of the tympanic membrane; it ranges from 60 to $99 \%$ in

(c) The Author(s). 2020 Open Access This article is licensed under a Creative Commons Attribution 4.0 International License, which permits use, sharing, adaptation, distribution and reproduction in any medium or format, as long as you give appropriate credit to the original author(s) and the source, provide a link to the Creative Commons licence, and indicate if changes were made. The images or other third party material in this article are included in the article's Creative Commons licence, unless indicated otherwise in a credit line to the material. If material is not included in the article's Creative Commons licence and your intended use is not permitted by statutory regulation or exceeds the permitted use, you will need to obtain permission directly from the copyright holder. To view a copy of this licence, visit http://creativecommons.org/licenses/by/4.0/. 
adults and from 70 to $91 \%$ in children [6]. Some authors support the early closure of TM defect in children, to prevent frequent infections and avoid the effect of hearing loss on speech and language development [7], despite reperforation following myringoplasty [8]. Various factors had been studied affecting the outcome of these surgical interventions which include surgical approac $h[8]$, site of perforation [9], size of perforation [10], graft [11-13], surgical technique $[14,15]$, and mastoidectomy [16].

A wide variety of grafting materials were used nowadays in myringoplasty including temporalis fascia, fat, perichondrium, and cartilage for the closure of TM perforations. Temporalis fascia (TF) is the most commonly used graft worldwide [17]. The problems with the use of fascia as a graft material are due to atrophy or shrinkage of graft or its non-vascularization leading to failure [18]. Due to these reasons, surgeons have advocated the use of more stable, less compliant materials like cartilage for the reconstruction of the TM perforation. Currently, cartilage tympanoplasty is variously recommended in high-risk perforations like subtotal or bilateral perforations, revision tympanoplasty, anterior perforation, coexisting craniofacial abnormalities, atelectatic ears, and cholesteatoma [19].

Currently, much of the relevant information is based on retrospective studies with conflicting result with rare studies evaluating the role of cortical mastoidectomy in children undergoing tympanoplasty. Resolving these conflicts will certainly help in better selection and care of patients.

The aim of this study is to evaluate and compare the two main factors affecting the surgical outcome of myringoplasty in children: type of graft and cortical mastoidectomy.

\section{Methods}

\section{Subjects}

This is a prospective randomized study including 200 patients with an age range of 10 to 16 years presented to the otorhinolaryngology clinic from 2014 to 2018. All the patients have chronic suppurative otitis media of tubotympanic type (CSOM-TT) with permanent perforation. In addition, their ear should be dry for at least 12 weeks with intact ossicular chain. Moreover, all patients have a normal/good Eustachian tube and cochlear function with no more than 10-40 $\mathrm{dB}$ conductive hearing loss.

Patients with cholesteatoma, contralateral ear with chronic otitis media, craniofacial abnormalities, and those having a history of previous ear surgery were excluded from the study.

The study protocol was approved by the Ethics Committee, and informed consents were obtained from the parents of all patients after explaining the study protocol and aims.

\section{Procedure}

All the patients were subjected to thorough history taking and full otorhinolaryngological examination including otoscopic examinations of both ears. The external auditory meatus and the tympanic membrane were examined, and the site of the perforation was noted.

Examination of all the ears was done under microscope prior to surgery to assess the tympanic membrane, site of the perforation, to rule out any other pathology and to assess the status of the ossicular chain.

Pure tone audiometry was performed for all subjects using a clinical audiometer, and preoperative air bone gap (ABG) was calculated by taking the averages of bone conduction in addition, air conduction at the frequencies of $500,1000,2000$, and $4000 \mathrm{~Hz}$.

Eustachian tube function was measured using a modified pressure equilibration inflation-deflation test. After confirmation of dryness of both the external and middle ear by otoscopy, a probe was inserted into the external auditory canal, and pressure was varied over $\pm 300 \mathrm{daPa}$. Each patient was asked to swallow three times at intervals of 3-5 s with nose and mouth closed. After each swallow, applied pressure was normalized. The residual pressure after three swallows was recorded. The pressure would drop if the Eustachian tube opens. When it closes, the pressure will stabilize again. This was done a couple of times to see some sort of stair step result on the screen. A normal response is obtained when going up the positive pressure to positive 400, and suddenly, the Eustachian tube does blow open; the pressure will go back down to zero.

Children meeting the inclusion criteria were randomly divided into four groups by simple random sampling method according to the operation done. Each group consisted of 50 patients:

Group I-myringoplasty by temporalis fascia graft with simple mastoidectomy technique

Group II-myringoplasty by tragal cartilage with simple mastoidectomy

Group III-myringoplasty by tragal cartilage graft technique

Group IV-myringoplasty by temporalis fascia technique

For all patients, the operation was done under general anesthesia after taking a written informed consent from the parents. A post-auricular approach was used supplemented with local infiltration of $2 \%$ lidocaine with 1 : 100000 epinephrine then temporalis fascia graft was taken by upward extension of post-auricular incision. Tragal cartilage was harvested with its perichondrium from the tragus of the same ear. Under operating microscope, myringoplasty was performed by using underlay technique. Mastoidectomy was done using electric drill also under microscopy. Stitches were removed after 1 week.

Follow-up was done weekly for the first 6 weeks postoperative and then monthly for 1 year. Pure tone audiometry was done for patients with successfully taken grafts after 6 months, and changes in hearing were compared with their preoperative audiogram. 
Table 1 Preoperative ABG for all patients

\begin{tabular}{lllllll}
\hline ABG (pre) & \multicolumn{5}{l}{ Groups } \\
\cline { 3 - 7 } & & Group I & Group II & Group III & Group IV & Total \\
\hline $10-20 \mathrm{~dB}$ & $N$ & 23 & 21 & 33 & 19 & 96 \\
$20-30 \mathrm{~dB}$ & $N$ & 27 & 28 & 17 & 25 & 97 \\
$30-40 \mathrm{~dB}$ & $N$ & 0 & 1 & 0 & 6 & 7 \\
Total & $N$ & 50 & 50 & 50 & 50 & 200 \\
Chi-square & $X^{2}$ & 21.540 & & & & \\
& $P$ value & $0.001 *$ & & & & \\
\hline
\end{tabular}

${ }^{*}$ means (statistically significant)

Surgical success was defined in our study as the repair of tympanic membrane perforation without re-perforation, retracted graft, or medialized graft.

\section{Statistical analysis}

Results were collected, tabulated, and statistically analyzed by using SPSS for Windows (version 18; SPSS Inc., Chicago, IL, USA). The pure tone average (PTA)-ABG for each audiogram, preoperative and postoperative PTA-ABG, and graft take results were compared between the four study groups using the $\chi^{2}$ test. The criterion for statistical significance was set as $P<0.05$ and $P<$ 0.001 for highly statistical significance.

\section{Results}

A total number of 200 patients were included in this study meeting the inclusion criteria. The mean age of the patients was 11.2 years with an age range of 8 to 16 years. One hundred and nine patients were males (54.5\%) while ninety-one were females (45.5\%). These patients were randomly selected for each of the four groups equally, with fifty patients in each group. Preoperative air bone gap of most patients (96.5\%) ranged from 10 to $30 \mathrm{~dB}$ as shown in Table 1 while air bone of the patients with successfully taken grafts are shown in Table 2 with no statistically significant difference ( $P$ value 0.594 ).

\section{Graft uptake results}

Graft was taken successfully in 170 patients with a success rate of $85 \%$. Thirty patients failed to take the graft

Table 2 Preoperative ABG for patients with successfully taken grafts

\begin{tabular}{lllllll}
\hline ABG (pre) & \multicolumn{5}{l}{ Groups } \\
\cline { 3 - 7 } & & Group I & Group II & Group III & Group IV & Total \\
\hline $10-20 \mathrm{~dB}$ & $N$ & 21 & 19 & 24 & 18 & 82 \\
$20-30 \mathrm{~dB}$ & $N$ & 24 & 25 & 18 & 21 & 88 \\
Total & $N$ & 45 & 44 & 42 & 39 & 170 \\
Chi-square & $X^{2}$ & 1.897 & & & & \\
& $P$ value & 0.594 & & & & \\
\hline
\end{tabular}

Table $\mathbf{3}$ The comparison as regards graft taking between study groups

\begin{tabular}{|c|c|c|c|c|c|c|c|c|}
\hline \multirow[t]{3}{*}{ Groups } & \multicolumn{6}{|c|}{ Taken graft } & \multirow{2}{*}{\multicolumn{2}{|c|}{ Chi-square }} \\
\hline & \multicolumn{2}{|l|}{ Yes } & \multicolumn{2}{|l|}{ No } & \multicolumn{2}{|c|}{ Total } & & \\
\hline & $\bar{N}$ & $\%$ & $\bar{N}$ & $\%$ & $\bar{N}$ & $\%$ & $\overline{x^{2}}$ & $P$ value \\
\hline I & 45 & 90.00 & 5 & 10.00 & 50 & 25.00 & 3.294 & 0.348 \\
\hline$\|$ & 44 & 88.00 & 6 & 12.00 & 50 & 25.00 & & \\
\hline III & 42 & 84.00 & 8 & 16.00 & 50 & 25.00 & & \\
\hline IV & 39 & 78.00 & 11 & 22.00 & 50 & 25.00 & & \\
\hline Total & 170 & 85.00 & 30 & 15.00 & 200 & 100.00 & & \\
\hline$I+I V$ & 84 & 84.00 & 16 & 16.00 & 100 & 50.00 & 0.039 & 0.843 \\
\hline$\|+\|$ & 86 & 86.00 & 14 & 14.00 & 100 & 50.00 & & \\
\hline Total & 170 & 85.00 & 30 & 15.00 & 200 & 100.00 & & \\
\hline $1+\|$ & 89 & 89.00 & 11 & 11.00 & 100 & 50.00 & 1.922 & 0.165 \\
\hline$I I I+I V$ & 81 & 81.00 & 19 & 19.00 & 100 & 50.00 & & \\
\hline Total & 170 & 85.00 & 30 & 15.00 & 200 & 100.00 & & \\
\hline
\end{tabular}

and were distributed as follows: five in group I, six in group II, eight in group III, and 11 in group IV.

There was no significant statistical difference when comparing myringoplasty using temporalis fascia (groups I + IV) to myringoplasty using cartilage (groups II + III) ( $P$ value 0.843$)$. Although the number of patients with graft success rate for patients with mastoidectomy techniques $(\mathrm{I}+\mathrm{II})$ (89 patients) is higher than that without mastoidectomy (III + IV) (89 versus 81 patients, respectively), there was no statistically significant difference when comparing ( $P$ value 0.165$)$ as shown in Table 3.

\section{Hearing outcome results}

The bone conduction threshold, the air conduction threshold, and the difference between the two

Table 4 The comparison between different groups as regards improvement of hearing

\begin{tabular}{|c|c|c|c|c|c|c|c|c|}
\hline \multirow[t]{3}{*}{ Groups } & \multicolumn{6}{|c|}{ Improved hearing } & \multirow{2}{*}{\multicolumn{2}{|c|}{ Chi-square }} \\
\hline & \multicolumn{2}{|l|}{$\overline{Y e s}$} & \multicolumn{2}{|l|}{ No } & \multicolumn{2}{|c|}{ Total } & & \\
\hline & $N$ & $\%$ & $\bar{N}$ & $\%$ & $\bar{N}$ & $\%$ & $x^{2}$ & $P$ value \\
\hline I & 41 & 91.11 & 4 & 8.89 & 45 & 26.47 & 29.889 & $<0.001^{*}$ \\
\hline$\|$ & 32 & 72.73 & 12 & 27.27 & 44 & 25.88 & & \\
\hline III & 21 & 50.00 & 21 & 50.00 & 42 & 24.71 & & \\
\hline IV & 37 & 94.87 & 2 & 5.13 & 39 & 22.94 & & \\
\hline Total & 131 & 77.06 & 39 & 22.94 & 170 & 100.00 & & \\
\hline$I+I V$ & 78 & 92.86 & 6 & 7.14 & 84 & 49.41 & 21.710 & $<0.001^{*}$ \\
\hline$\|+\| I$ & 53 & 61.63 & 33 & 38.37 & 86 & 50.59 & & \\
\hline Total & 131 & 77.06 & 39 & 22.94 & 170 & 100.00 & & \\
\hline$I+\|$ & 73 & 82.02 & 16 & 17.98 & 89 & 52.35 & 2.047 & 0.152 \\
\hline$I I I+I V$ & 58 & 71.60 & 23 & 28.40 & 81 & 47.65 & & \\
\hline Total & 131 & 77.06 & 39 & 22.94 & 170 & 100.00 & & \\
\hline
\end{tabular}

*means (statistically significant) 


\section{Distribution of improved hearing among groups}

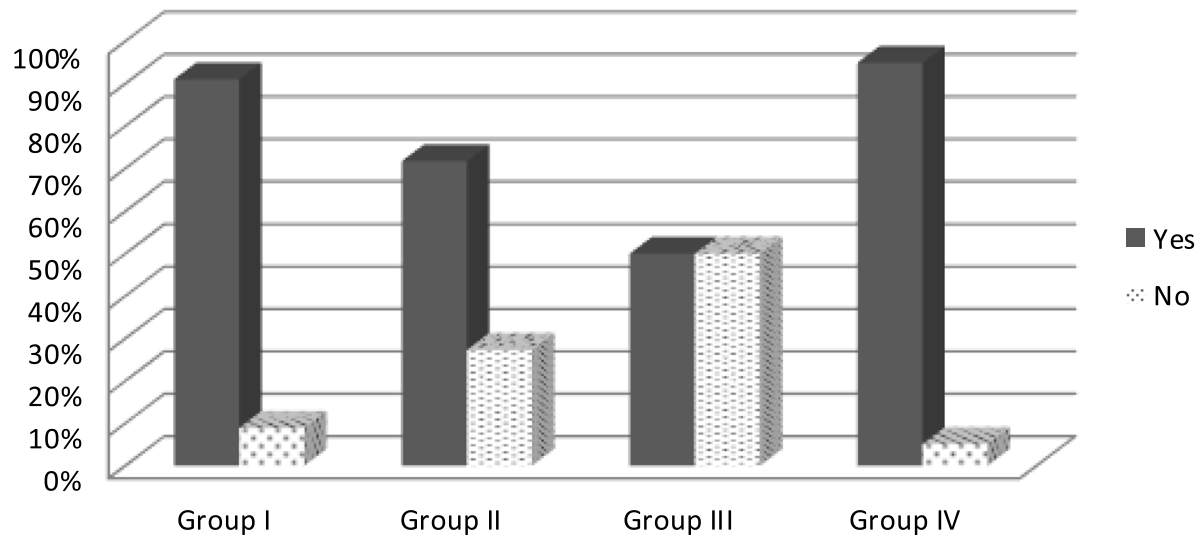

Fig. 1 The distribution of improved hearing among groups

calculated as air bone gap (ABG) were measured postoperatively for patients with successfully taken graft after 6 months.

The hearing was improved postoperatively (131 patients) in all groups (77\%). Twenty-one patients out of the 39 patients $(53 \%)$ whose hearing did not show any improvement were in group III. Group IV had the highest percentage of hearing improvement $(P$ value $<0.001)$ as shown in Table 4 and Fig. 1.

On comparing the two types of grafts as regards improvement of hearing, myringoplasty using temporalis fascia (groups I + IV) $(P<0.001)$ showed highly statistically significant difference as shown in Table 4 and Fig. 2. On the other hand, there was no statistically significant difference when comparing the technique (with versus without mastoidectomy) ( $P$ 0.152) as shown in Table 4.

\section{Discussion}

The study we conducted was prospective and randomized. This was a stronger study associated with less chance of selection bias. Reviewing the literature, there is only one study done in adults that was prospective and randomized study. However, most of the studies were retrospective, not randomized and rare studies evaluate simple cortical mastoidectomy in children who underwent myringoplasty. Although we have used different approaches for myringoplasty, the study done comparing outcome of myringoplasty with different surgical approaches has shown no difference in graft uptake rate [20].

Different types of graft materials were used to reconstruct the tympanic membrane. The choice of graft material depends on the surgeon's experience and his/her personal choice, as there are no solid indications to date to prefer

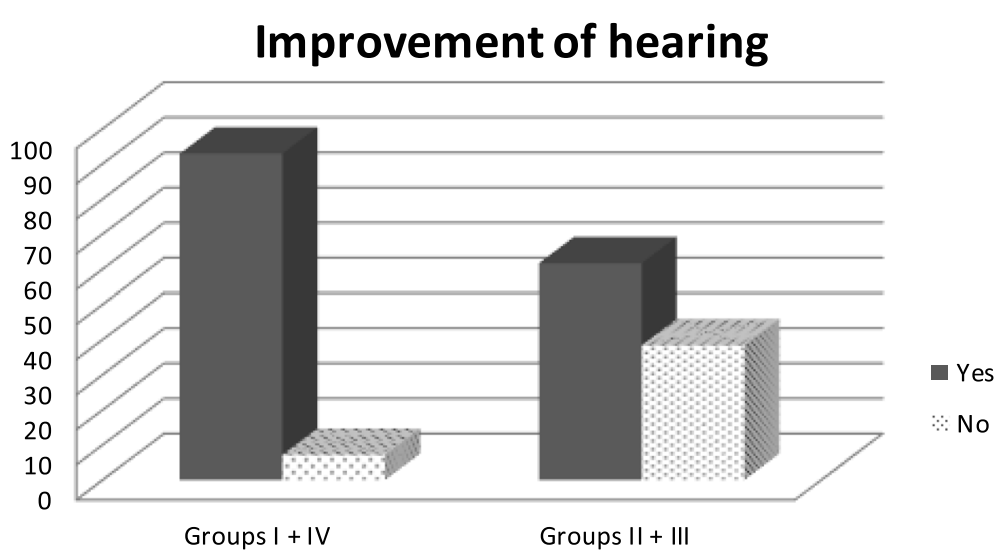

Fig. 2 The comparison between the 2 types of grafts as regards improvement of hearing 
one type to the other. We aimed in our prospective randomized study at comparing the effectiveness of the use of cartilage versus temporalis fascia in myringoplasty with or without mastoidectomy in children as regards two aspects: graft uptake rate and hearing improvement with a 1-year follow-up postoperatively. We found that both cartilage and temporalis fascia grafts used in tympanoplasty give comparable results as regards graft uptake with no statistically significant result (0.0843). However, fascia graft showed better results and with statistically significant difference in respect to hearing improvement $(P<0.001)$.

Tripathi et al. [6] in a prospective randomized study on 47 Nepali children found no significant difference between cartilage and temporalis fascia as regards graft uptake and hearing improvement. However, their sample was small with a short period follow-up which was 6 weeks postoperative in comparison to our sample which was 200 patients with 1-year follow-up.

A retrospective study done by Ozbek et al. [21] on 45 Turkish child who had undergone myringoplasty with cartilage or temporalis fascia found after a mean followup of 19 months that there is a statistically significant difference $(P=0.008)$ between $100 \%$ graft uptake in the cartilage group and $70 \%$ in the temporalis fascia group. In contrast to our prospective randomized study, there was no statistically significant difference between cartilage and fascia after 12 months follow-up.

Moreover, in another retrospective study comparing cartilage and temporal fascia graft in type 1 tympanoplasty for bilateral perforations in children, Gun et al. [22] found no statistically significant difference between fascia and cartilage. The mean follow-up in the fascia group was 23.2 months, and that for the cartilage was 21.9 months.

Cortical mastoidectomy in combination with myringoplasty has been recommended by many authors to increase graft success in adults especially in high-risk tympanoplasty such as revision cases and chronic draining ears [23]. Their opinion was primarily based on the fact that mastoidectomy improves the middle ear and mastoid environment through clearance of diseased secretory mucosa and the ventilator mechanisms of an open mastoid system [24]. Although cortical mastoidectomy is a safe procedure in children with no persistent complications [25], only very few studies were done to evaluate its role in children.

Among the children with chronic otitis media with perforation, Yoon et al. [26] retrospectively found 100\% surgical success rates of tympanoplasty with cortical mastoidectomy in 20 ears after 1-year follow-up.

In a long-term follow-up for evaluation of mastoidectomy in children with chronic otitis media, Rickers et al. [25] demonstrated that surgical intervention did not completely cure the chronicity of the middle ear.

Finally, in our study, we found the number of patients with graft success rate with mastoidectomy ( 89 patients) is higher than that without mastoidectomy (81 patients); however, there was no significant statistical difference between them. In addition, there was no significant statistical difference as regards hearing outcome.

\section{Conclusion}

Tympanoplasty using temporalis fascia without cortical mastoidectomy is the surgery of choice in children between 10 and 16 years old with tympanic membrane perforation as it showed highly statistically significant difference as regards hearing improvement with no statistically significant difference regarding successful graft uptake. Cortical mastoidectomy did not give superior results when combined to tympanoplasty.

\section{Abbreviations}

ABG: Air bone gap; COM: Chronic otitis media; CSOM-TT: Tubotympanic chronic suppurative otitis media; PTA: Pure tone audiometry; TM: Tympanic membrane

\section{Acknowledgements}

Not applicable.

\section{Authors' contributions}

AK and TS contributed to the following: idea, protocol, patient selection, surgery, follow-up, data analysis, and writing the manuscript. PA contributed to the idea, protocol, preoperative and postoperative hearing tests, and manuscript writing. All authors read and approved the final manuscript.

\section{Funding}

There was no funding.

\section{Availability of data and materials}

The datasets used and/or analyzed during the current study are available from the corresponding author on reasonable request.

\section{Ethics approval and consent to participate}

Approval of the Ethics Committee of Ain Shams University Hospital in 2014. Reference number is not available. Informed written consent was obtained from the parents of all patients to participate in the study.

Consent for publication

Not applicable.

\section{Competing interests}

The authors declare that they have no competing interests.

Received: 26 March 2020 Accepted: 20 May 2020

Published online: 29 July 2020

\section{References}

1. Telian S. A, Schmalbach C. E. Chronic otitis media, in: J.B. Snow, J.J. Ballenger (Eds.), Ballenger's otorhinolaryngology: head and neck surgery, 16th ed., BC Decker Inc., Spain, 2003, pp. 261-293.

2. Browning G. G, Merchant S. N, Kelly G., Swan L. R., Canter R., McKerrow W. S. Chronic otitis media, in: M. Gleeson, G.G. Browning, M.J. Burton, R. Clarke, J. Hibbert, N.S. Jones, et al. (Eds.), Scott-Brown's otorhinolaryngology: head and neck surgery, 7th ed, Edward Arnold (publishers) Ltd, London, 2008, pp. 3395-3446.

3. Knapik M, Saliba I (2011) Pediatric myringoplasty: a study of factors affecting outcome. Int J Pediatr Otorhinolaryngol 75:818-823

4. Mehta RP, Rosowski JJ, Voss SE, O'Neil E, Merchant SN (2006) Determinants of hearing loss in perforations of the tympanic membrane, Otol. Neurotol 27(2):136-143

5. Sharma DK, Singh S, Sohal BS, Singh B (2009) Prospective study of myringoplasty using different approaches. Ind Journal of Otolaryngology and Head and Neck Surg 61:297-300 
6. Tripathi P, Guragain RP, Bhusal CP, Karna SL, Borgstein J (2015) A comparison of two myringolasty techniques in Nepalese children: a prospective randomised trial. Int I Pediatr Otorhinolaryngol 79:1556-1560

7. Umapathy N, Dekker PJ (2003) Myringoplasty is it worth performing in children. Arch Otolaryngol Head Neck Surg 129:1053-1055

8. Inwood JL, Wallace HC, Clarke SE (2003) Endaural or postaural incision for myringoplasty: does it make a difference to the patient? Clin Otolaryngol 28:396-398

9. Hung T, Knight JR, Sankar V (2004) Anterosuperior anchoring myringoplasty technique for anterior and subtotal perforations. Clin Otolaryngol 29:210-214

10. Lee P, Kelly G, Mills RP (2002) Myringoplasty: does the size of the perforation matter? Clin Otolaryngol 27:331-334

11. Pfleiderer AG, Moffat D (1988) The Fasciaform graft: a technique for the repair of large perforatinos of the tympanic membrane. Clin Otolaryngol 13: 427-434

12. Mohamad SH, Khan I, Musheer H (2012) Is cartilage tympanoplasty more effective than fascia tympanoplasty? A systematic review. Otol Neurotol 33: 699-705

13. Yung M, Vivekanandan S, Smith P (2011) Randomized study comparing fascia and cartilage grafts in myringoplasty. Ann Otol Rhinol Laryngol 120: 535-541

14. Couloigner V, Baculard F, El Bakkouri W et al (2005) Inlay butterfly cartilage tympanoplasty in children. Otol Neurotol 26:247-251

15. Cabra J, Monoux A (2010) Efficacy of cartilage palisade tympanoplasty: randomised controlled trial. Otol Neurotol 31:589-595

16. MutohT AO, Tsuji $\mathrm{K}$ et al (2007) Efficacy of mastoidectomy on MRSAinfected chronic otitis media with tympanic membrane perforation. Auris Nasus Larynx 34:9-13

17. Aggarwal R, Saeed SR, Green KJM (2006) Myringoplasty. The Journal of Laryngology \& Otology 120:429-432

18. Sarkar S, Roychoudhury A, Roychaudhuri BK (2009) Tympanoplasty in children. Eur Arch Otorhinolaryngol 266:627-633

19. Uslu C, Tek A, Tatlipinar A, Kilicarslan Y, Durmus R, Ayogredik E et al (2010) Cartilage reinforcement tympanoplasty: otological and audiological results. Acta Otolaryngol 130:375-383

20. Halim A, Borgstein J (2009) Pediatric myringoplasty: postaural versus transmeatal approach. Int J Pediatr Otorhinolaryngol 73:1580-1583

21. Ozbek C, Ciftci O, Tuna EEU, Yazkam O, Ozdem C (2008) A comparison of cartilage palisades and fascia in type I tympanoplasty in children: anatomic and functional results. Otol Neurotol 29:679-683

22. Gun T, Boztepe OF, Atan D, Aykut I, Dere H (2017) A comparison of cartilage Palisades and temporal fascia in type 1 tympanoplasty for bilateral tympanic membrane perforations in children. The journal of international advanced otology 13(1):36-39

23. McGrew BM, Jackson CG, Glascock ME (2004) Impact of mastoidectomy on simple tympanic membrane perforation repair. Laryngoscope 114:506-511

24. Toros SZ, Habesoglu TE, Habesoglu M, Bolukbasi S, Naiboglu B, Karaca CT, Egeli E (2010) Do patients with sclerotic mastoids require aeration to improve success of tympanoplasty? Acta Otolaryngol 130:909-912

25. Rickers J, Petersen CG, Pedersen CB, Ovesen T (2006) Long term follow up evaluation of mastoidectomy in children with non-cholesteatomatous chronic suppurative otitis media. Int J Pediatr Otorhinolaryngol 70:711-715

26. Yoon TH, Park S, Kim JY, Pae KH, Ahn JH (2007) Tympanoplasty, with or without mastoidectomy, is highly effective for treatment of chronic otitis media in children. Acta Otolaryngol 558:44-48

\section{Publisher's Note}

Springer Nature remains neutral with regard to jurisdictional claims in published maps and institutional affiliations.

\section{Submit your manuscript to a SpringerOpen ${ }^{\circ}$ journal and benefit from:}

- Convenient online submission

- Rigorous peer review

- Open access: articles freely available online

High visibility within the field

- Retaining the copyright to your article

Submit your next manuscript at $\boldsymbol{\nabla}$ springeropen.com 